\title{
Transient global amnesia: neuropsychological dysfunction during attack and recovery in two "pure"
} cases

\author{
MARIANNE REGARD, THEODOR LANDIS \\ From the University Hospital, Department of Neurology, Zürich, Switzerland
}

SUMMARY Two patients with transient global amnesia are reported. Comprehensive neuropsychological evaluation, during the amnesic episode, as well as follow-up examinations on memory were performed. The course of the amnesia was exemplified by two comparable memory tests in different modalities. Partial retrograde amnesia and complete anterograde amnesia were demonstrated during the transient episode. Objective recovery was found to be slower than subjectively experienced, but test performance was completely normal one month after onset.

Bender ${ }^{1}$ was the first to describe transient confusion and amnesia in 12 cases. Numerous reports followed and in 1964, Fisher \& Adams $^{2}$ first reviewed the literature and labelled the syndrome transient global amnesia. Of the many reported cases with transient global amnesia only six $^{3-7}$ had some neuropsychological assessment during the amnesic phase, one of which had been reexamined 1 week and 6 months later, the other 15 months later. ${ }^{57}$ Neuropsychological assessment during the episode and close follow-up examinations on patients with transient global amnesia are of special interest since neurological examination as well as other diagnostic methods such as EEG and CT scan are usually normal. Objective test results may contribute to differential diagnosis especially from confusion states of other origins.

We report two patients with transient global amnesia in whom comprehensive neuropsychological evaluation during the attack as well as repeated memory testing during recovery were possible. The course of the amnesia is exemplified by two comparable memory tests.

This study was supported by the Swiss National Science Foundation Grant Nr. 3.867-0.81.

Address for reprint requests: Dr M Regard, Universitätsspital, Neurologische Klinik, Rä mistr. 100, CH-8091 Zü rich, Switzerland.

Received 25 October 1983 and in revised form 9 January 1984. Accepted 10 January 1984
Case 1

This was a 40-year-old healthy right-handed policeman and former high school teacher without vascular risk factors and with an uneventful medical history. During gymnastics he suddently became confused. Back at work again he kept asking the same questions over and over in an attempt to orient himself. He called his wife who immediately brought him to the local physician who noticed no neurological abnormalities and prescribed co-degocrine mesylate. Back home, the patient complained about feeling a bruise in the back of his head. He then drove himself miles through heavy traffic to the hospital without difficulty. On admission neurological examination, EEG, CT scan and cerebro-vascular Doppler sonography were completely normal. On mental status examination, the patient was disoriented in time but not in space. He appeared confused and asked the same question over and over, but was able to maintain a coherent train of thought. His retrograde amnesia was of several months with only fragments in between and there was a complete anterograde amnesia. There was, however, no confabulation and the patient showed a completely normal social interaction and an adequate concern about his disability. He spontaneously reported difficulties in remembering the chronological order of events, for example he knew the colour and type of his car, but did not know whether he owned it at present or did previously. He was aware of being in the hospital because he remembered having watched a helicopter landing, but he was unable to indicate whether this event took place a few minutes ago, a few hours ago or on a previous day. This kind of defect was no longer apparent 72 hours after onset of the episode. Extensive clinical neuropsychological evaluation of higher cortical functions was performed on admission during the episode ( $2 \frac{1 / 2}{2}$ hours after onset): questions referring to autobiographical and public events revealed a retrograde amnesia of several months. Anterograde amnesia was 668 
tested with two comparable tests, the Rey auditory-verbal test and the Rey visual learning test. ${ }^{8}$ In the verbal test, 15 words are read to the patient, which he then has to repeat from memory. This is repeated 5 times (learning) and after $40 \mathrm{~min}$, the patient has to recall as many words as possible. In the visual learning test, 15 figures are presented one at the time and the patient has to draw them. This is repeated 5 times and after $40 \mathrm{~min}$, recall is requested. In the verbal task, the patient recalled $4,6,5,6,5$ in the learning phase and recalled none after $\mathbf{4 0} \mathrm{min}$. In the visual task, he recalled $1,2,4,2,3$ and later 5. Digit span forward was 7, backward 5 , visual span was 6 . The Rey complex Figure ${ }^{910}$ was copied without errors, but 90 min later, only three elements (out of 18) were recalled and the main structure of the figure was rotated by 90 degrees. He could draw a Necker cube without difficulty and there were no signs of buccofacial, ideomotor and ideational apraxia. Objects, colours and famous faces he recognised and named instantly. Spontaneous speech, comprehension and repetition were normal, so was writing and visual and auditory reading. Verbal and nonverbal fluency and the Stroop Color Word Test ${ }^{1112}$ were normal.

Except for memory all other clinically evaluated higher cortical functions were normal. Therefore, the course of recovery was followed with two parallel versions of the two memory tests and the Rey complex Figure at 9, 24, 48, 72 hours, and 1 month after onset of the amnestic episode. The memory performance of all examinations is summarised in the table.

Nine hours after onset, the retrograde amnesia shrank to about 2 days prior to the episode. Verbal learning improved $(5,6,5,6,7,10)$, but there was no recall. Of the 15 figures he recalled only three. The copy and recall of the Rey complex Figure was practically identical to the first testing: it was still rotated and he remembered five elements and displaced three. Inquiry revealed still defective time perception. Twenty-four hours past onset, there was improved verbal learning $(7,11,12,13,14)$, but recall was only nine. Of the 15 figures he now learned $8,10,13,11$, 13 and recalled later 11 correctly. Again, the Rey Figure was rotated. Time perception was still defective. Fortyeight hours past onset, there was amnesia for the length of the episode (ca 3 hours). Verbal learning was 8, 9, 12, 12, 13 , recall nine, visual learning was $9,11,14,13,13$ and recall 14 . Of the correctly copied Rey Figure he remembered eight elements and displaced one without rotation. Seventy-two hours past onset, verbal learning was 8, 9, 12, 14,13 and late recall eight, visual learning was $13,14,15$, 14,15 and recall 14. One month after onset, all functions recovered: verbal learning was now $8,13,14,14,13$, recall 12 , visual learning was $14,15,15,15,15$ and all 15 figures recalled later. Of the Rey Figure he recalled 15 elements and displaced only one element, without rotation. The amnesia for the length of the episode remained.

\section{Case 2}

This was a 60-year-old right-handed railway supervisor without vascular risk factors and with an uneventful medical history, except for transient global amnesia nine months prior to admission. He suddenly became confused while bending over while washing his car and he repeated questions over and over. His wife brought him immediately to the hospital for an EEG as she was instructed after the earlier attack in case of the recurrence of a similar event. On admission neurological examination, EEG, CT scan as well as cerebro-vascular Doppler sonography were normal. On mental status examination the patient was disoriented in time but not in space, he appeared confused and repeated the same questions. No confabulation was noted. His fragmentary retrograde amnesia was of several months and there was a complete anterograde amnesia. Social interaction and affective behaviour were normal. As in the first case, this patient also spontaneously reported to have no sense for time estimation, for example, he remembered his two daughters, knew their names, but was unable to say who was born first. He knew the facts of events but not the time of their occurrence, for example, he remembered having eaten breakfast, but not whether this was just a few minutes or a few hours ago despite his correct time calculation by consulting his watch. His disturbed time perception was no longer apparent after 3 days. Similar neuropsychological evaluation as in case 1 was performed during episode ( $2 \frac{1}{2}$ hours after onset): there was a fragmentary retrograde amnesia of several months. There was an

Table Summary of the memory defects during the episode and follow-up for case 1 and case 2

\begin{tabular}{|c|c|c|c|}
\hline Time after onset & & Case 1 & Case 2 \\
\hline (during episode) & $\begin{array}{l}\text { retrograde } \\
\text { anterograde }\end{array}$ & $\begin{array}{l}\text { present } \\
\text { defective verbal and visual learning and recall, in } \\
\text { Rey Complex Figure } 90^{\circ} \text { rotation } \\
\text { time perception defective }\end{array}$ & $\begin{array}{l}\text { present } \\
\text { defective verbal and visual learning and recall, in } \\
\text { Rey Complex Figure } 90^{\circ} \text { rotation }\end{array}$ \\
\hline $9 \mathrm{hr}$. & $\begin{array}{l}\text { immediate span } \\
\text { retrograde } \\
\text { anterograde }\end{array}$ & $\begin{array}{l}\text { normal auditory-verbal and visuo-spatial span } \\
\text { present (improved) } \\
\text { no change, Rey Figure still rotated } \\
\text { time perception still defective }\end{array}$ & $\begin{array}{l}\text { normal auditory-verbal and visuo-spatial span } \\
\text { present (improved) } \\
\text { no change, Rey Figure still rotated } \\
\text { time perception still defective }\end{array}$ \\
\hline $24 \mathrm{hr}$. & retrograde & present (improved) & present (improved) \\
\hline $48 \mathrm{hr}$. & $\begin{array}{l}\text { anterograde } \\
\text { retrograde } \\
\text { anterograde }\end{array}$ & $\begin{array}{l}\text { no change } \\
\text { amnesia for length of episode: ca. } 3 \mathrm{hr} \text {. } \\
\text { improved, Rey Figure no longer rotated } \\
\text { time perception defective }\end{array}$ & $\begin{array}{l}\text { verbal learning improved } \\
\text { amnesia for length of episode: ca. } 6 \mathrm{hr} \text {. } \\
\text { improved, Rey Figure no longer rotated } \\
\text { time perception defective }\end{array}$ \\
\hline $72 \mathrm{hr}$. & $\begin{array}{l}\text { retrograde } \\
\text { anterograde }\end{array}$ & $\begin{array}{l}\text { amnesia for length of episode } \\
\text { learning intact, verbal recall still defective } \\
\text { time perception normal }\end{array}$ & $\begin{array}{l}\text { amnesia for length of episode } \\
\text { learning intact, verbal recall still defective } \\
\text { time perception normal }\end{array}$ \\
\hline 1 mon & & $\begin{array}{l}\text { total recovery except for remaining amnesia for } \\
\text { length of episode. }\end{array}$ & $\begin{array}{l}\text { total recovery except for remaining amnesia for } \\
\text { length of episode. }\end{array}$ \\
\hline
\end{tabular}


Rey auditory verbal learning and recall
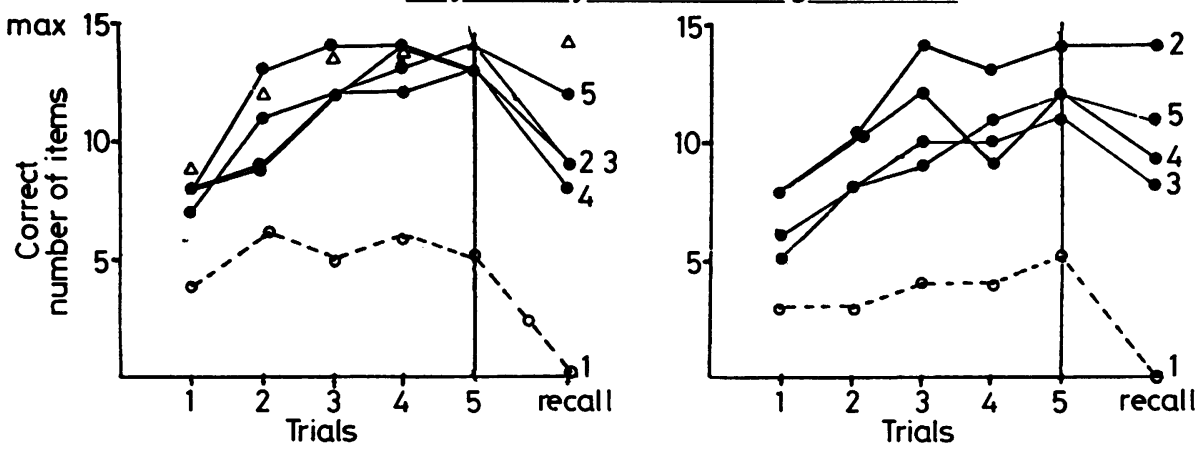

1 during episode

2 24h post

$348 \mathrm{~h}$ post

$472 \mathrm{~h}$ post

Rey visual learning and recall
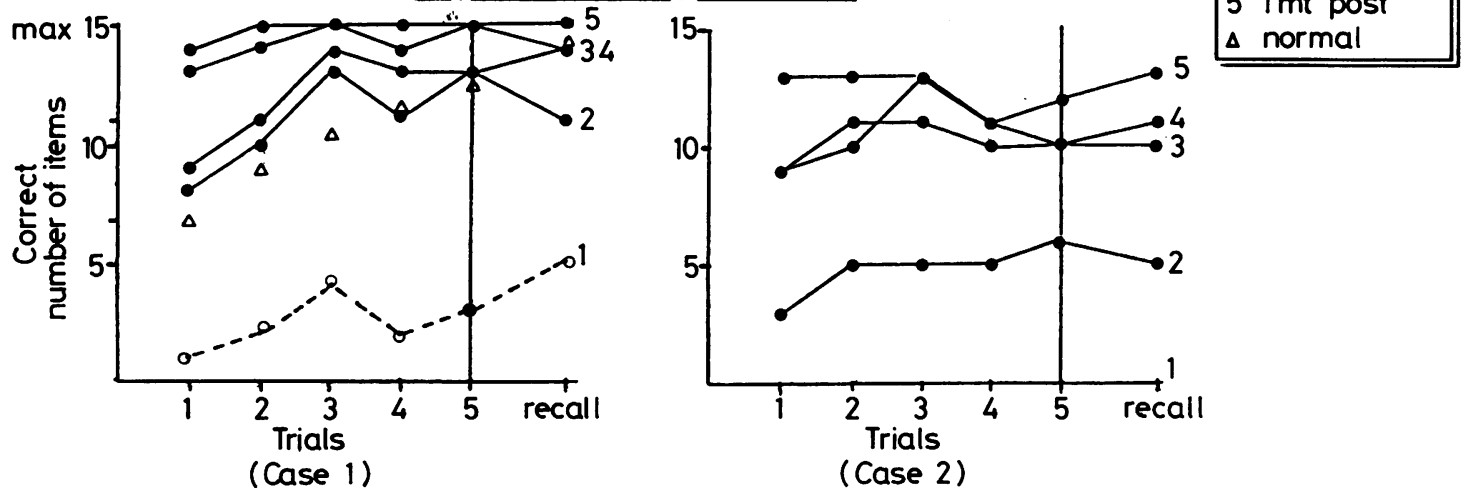

Fig 1 Rey auditory verbal learning and recall and Rey visual learning and recall during the episode and follow-up in 2 cases with transient global amnesia.

anterograde amnesia: the Rey verbal learning for the five phases was $3,3,4,4,5$ and there was no recall, and of the 15 figures he recalled none. Of the Rey Figure he copied 17 elements and slightly displaced four, recall was rotated by 90 degrees, four elements remembered and two displaced. Immediate span, language, praxis, gnosis, writing and reading were normal. Verbal and nonverbal fluency and the Stroop test were normal. Besides the amnestic syndrome, there were no other higher cortical defects. Therefore, only memory tests were performed after 9,24 , 48,72 hours, and 1 month after onset, as in case 1 . The memory performance of all examinations is summarised in the table.

Nine hours after onset, the retrograde amnesia shrank to about 1 month prior. to the episode, all other functions were similar to the first testing. Twenty-four hours after onset, the retrograde amnesia shrank to the evening prior to the episode (ca. 15 hours). Verbal learning improved (8, $10,14,13,14)$, recall was 14 , visual learning was still poor $(3,5,5,5,6)$, recall five. Of the correctly copied figure he recalled four elements and displaced one. Forty-eight hours after onset, amnesia left only for the length of the episode (ca. 6 hours). Verbal learning was 6, 8, 10, 10, 11 and late recall eight, visual learning was $9,10,13,11,10$ and late recall 10 . Of the correctly copied Rey Figure, he recalled seven elements with the main structure still rotated. Time estimation was still insecure. Seventy-two hours after onset, verbal learning was $8,10,12,9,12$ late recall nine, visual learning was $9,11,11,10,10$, late recall 11 . Of the Rey Figure he remembered five elements. One month after onset, the amnesia remained for the length of the episode. Of the 15 words he learned now $5,8,9,11,12$ and recalled later 11 , of the 15 figures he kept 13,13,13,11, 12 and recalled 13. Of the Rey Figure he recalled 13 and displaced three elements.

Figure 1 illustrates the recovery course of the anterograde amnesia for the two comparable memory tests, the Rey auditory verbal test and the Rey visual learning test. In fig 2 , the copy and recall with the 90 degree rotations of the Rey Complex Figure are illustrated.

\section{Conclusions}

Both our cases are strikingly "pure" examples of transient global amnesia displaying no neurological and neuropsychological abnormalities other than a defect in memory. Their test performance during the episode as well as their recovery course were almost identical, that is characterised by a sudden onset, a 

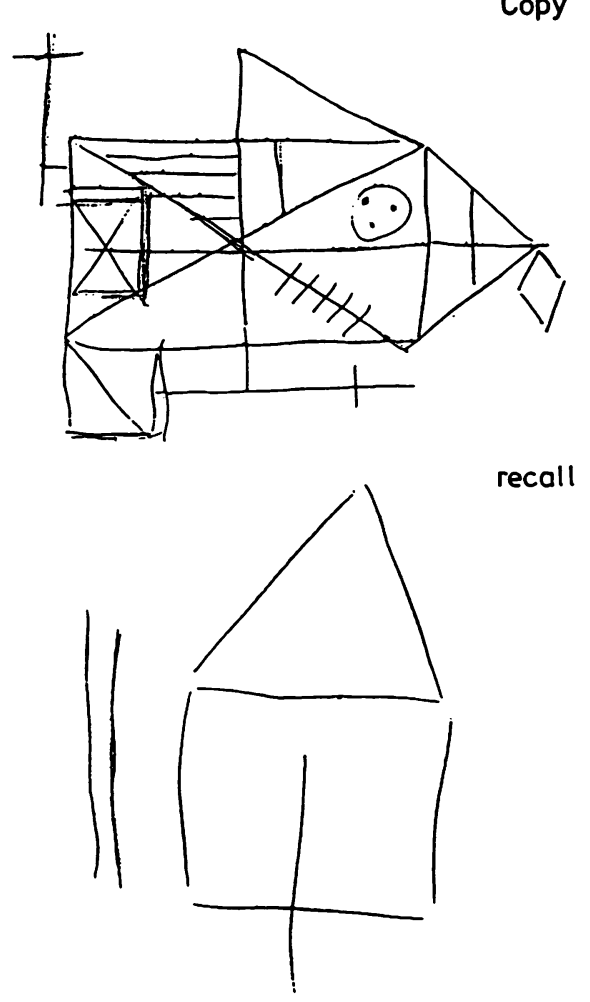

recall

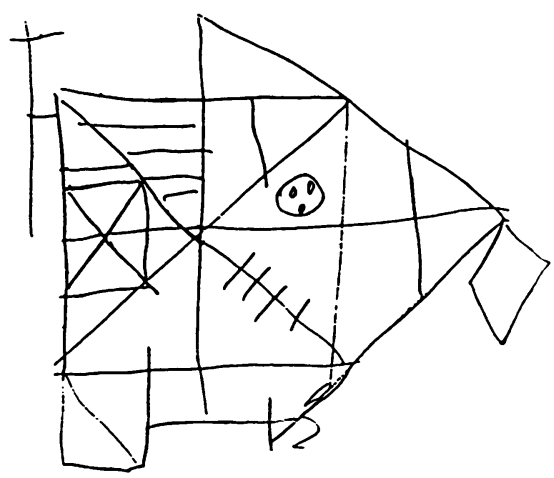

(case 1 )

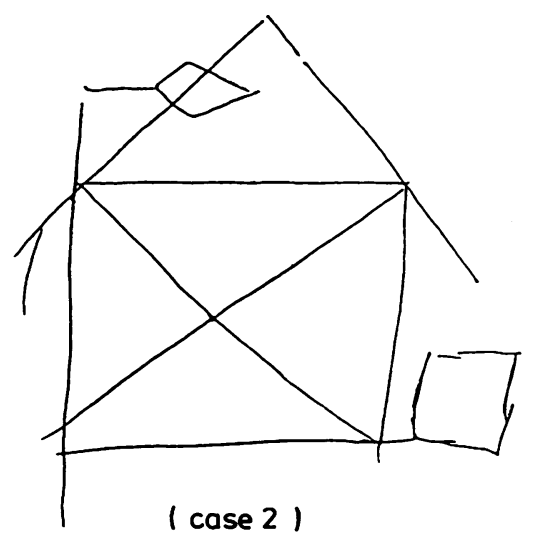

Fig 2 Copy and recall (90 min later) of the Rey complex Figure during the transient global amnesia episode demonstrating a $90^{\circ}$ rotation in recall.

retrograde amnesia with more severe impairment of recently acquired memories that older memories and a recovery within 2 days. The anterograde amnesia improved after the first day but normalised only after 1 month despite the subjective feeling of complete recovery after the first day. In both cases, however, a permanent amnesia for a few hours persisted. Moreover, for the first 72 hours from onset of the episode, both patients clearly remembered some events but complained of an inability to place them in chronological order. This failure to encode the temporal relations among events was recently discussed in detail by Hurst \& Volpe. ${ }^{13}$ This defect alone could explain sufficiently the temporary failure to integrate new and retrieve old information during the episode as well as the confusional state. Consequently, we found a dissociation between impaired episodic memory, that is, memory for events that are tied to a temporal and spatial context, and an unaffected semantic memory, that is, memory for automised knowledge such as intact motor and social programs and the recognition of famous faces. Furthermore, both cases recalled the normally copied Rey Complex Figure in 90 degree rotation. In adult brain damaged patients, this specific kind of rotation seems not to be a direct perceptual defect and is most frequently observed in patients with lesions in the right temporal-basal area. ${ }^{10}$ Immediate span was intact as well as other higher cortical functions.

The results of our investigation show that except for the shortness of the episode, the pattern of memory disturbance in transient global amnesia is the same as that in other amnesic syndromes, and reasonably, the same neuroanatomical structures or pathways may be compromised. However, the present results also show that even with refined neuropsychological testing, complete recovery is possible. This differs from the findings of Mazzucchi et $a^{14}$ who still obtained neuropsychological defects in follow-up investigations in 16 patients. On the other hand, by following the course of recovery especially 
during the first days after onset, we could also demonstrate that complete normalisation of the retrograde amnesia (ca. after 2 days) and the anterograde amnesia (ca. after one month) takes in fact longer than subjectively experienced.

\section{References}

' Bender MB. Syndrome of isolated episode of confusion with amnesia. J Hillside Hosp 1956;5:212-5.

${ }^{2}$ Fisher CM, Adams RD. Transient global amnesia. Acta Neurol Scand 1964;40: (Suppl 9).

${ }^{3}$ Patten BM. Transient global amnesia syndrome. JAMA 1973;217:690-1.

${ }^{4}$ Shuttleworth EC, Wise GR. Transient global amnesia due to arterial embolism. Arch Neurol 1973; 29:3402.

${ }^{5}$ Gordon B, Marin OSM. Transient global amnesia: an extensive case report. J Neurol Neurosurg Psychiatry 1979; 42:572-5.

${ }^{6}$ Wilson RS, Koller W, Kelly MP. The amnesia of transient global amnesia. J Clin Neuropsychol 1980;2:259-66.
7 Caffarra P, Moretti G, Mazzucchi A, Parma M. Neuropsychological testing during a transient global amnesia episode and its follow-up. Acta Neurol Scand 1981;63:44-50.

${ }^{8}$ Rey A. L'examen Clinique en Psychologie. Paris: Presses Universitaire de France, 1964.

9 Osterrieth PA. Le test de copie d'une figure complexe. Arch Psychol 1944;30:206-356.

${ }^{10}$ Regard M. (Rotation in the copy and recall of visual stimuli in brain damaged patients). Paper presented at the Tagung experimentell arbeitender Psychologen, Bochum, 1976.

"Perret E. The left frontal lobe of man and the suppression of habitual responses in verbal categorical behaviour. Neuropsychologia 1974;12:323-30.

12 Regard M, Strauss E, Knapp P. Children's production on verbal and non-verbal fluency. Percept Mot Skills 1982; 55:839-44.

${ }^{13}$ Hurst W, Volpe BT. Temproal order judgements with amnesia. Brain and Cognition 1982;1:294-306.

${ }_{14}$ Mazzucchi A, Moretti G, Caffarra P, Parma M. Neuropsychological functions in the follow-up of transient global amnesia. Brain 1980;103:161-78. 